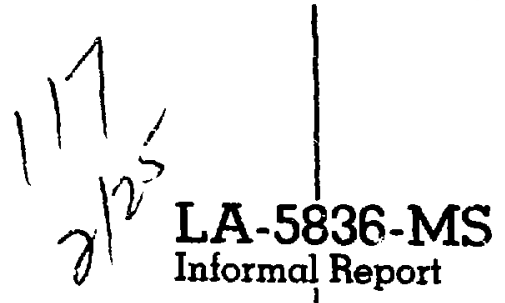

Reporting Date: December 1974

Issued: January 1975

\title{
Neutron Energy and Velocity Distributions from Thermal D-T Reactions
}

by

\author{
D. A. Marshall
}

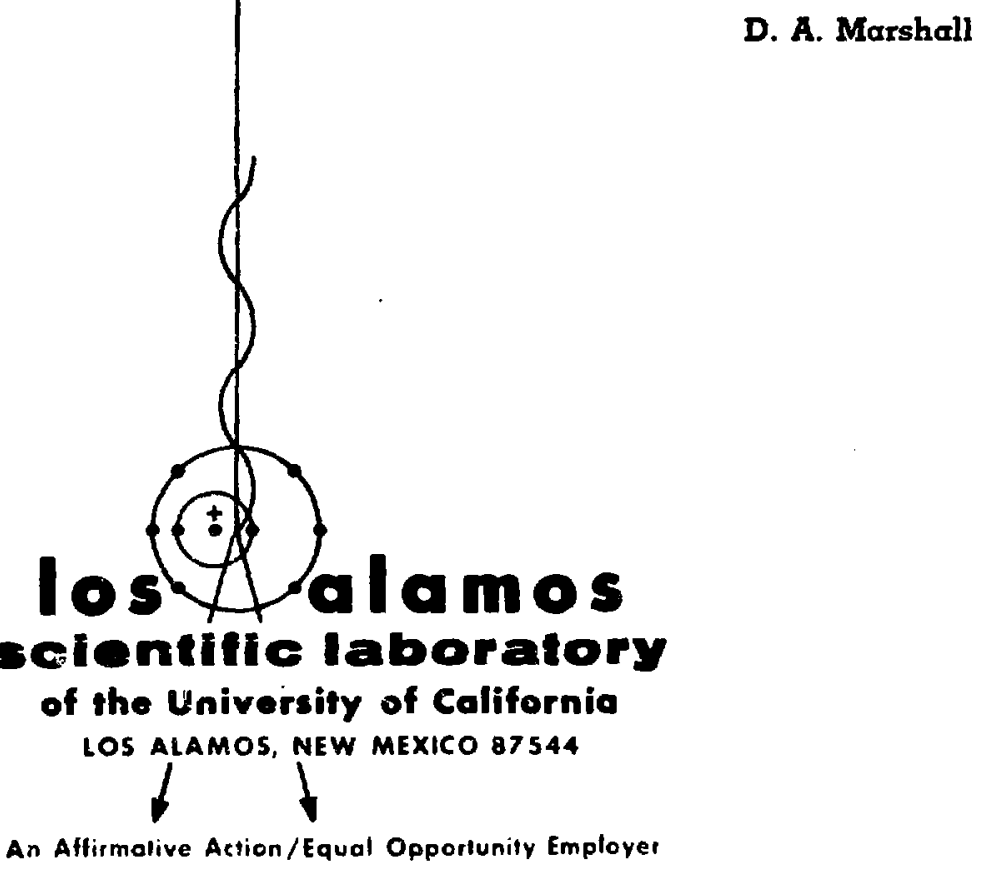


In the interest of prompt distribution, this LAMS report was not edited by the Technical Information stall.

This work was supported by the Defense Nuclear Agency.

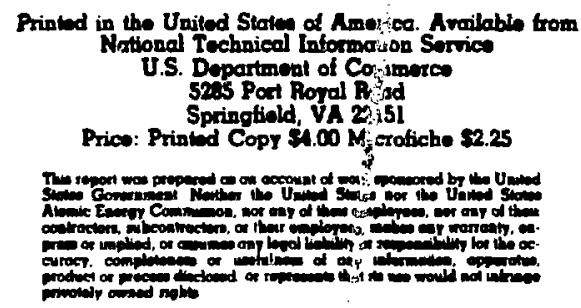


NEUTRON ENLRGY AND VELOCITY DISTRIBUTIONS FROM THERMAL D-T REACTIONS

by

D. A. Marshall

ABSTRACT

This report collects a number of general formulae which apply to the determination of the neutron energy and velocity distributions from the therinal D-T reaction. Comparison of the predictions of these formulae with the results of a Monte Carlo calculation suggests that the formulae apply to temperatures in excess of $100 \mathrm{keV}$.

\section{INTRODUCTION}

Section 11 presents the general formulae applying to the thernal D-T $\rightarrow \mathrm{n} \times$ reaction. Section $11 \mathrm{l}$ applies these formulae and compares their predictions to a Monte Carlo calculation of the energy and velocity distributions.

I1. GENERAL FORMULAF

For reaction 1

$$
1+3 \rightarrow 3+4
$$

the relativistic energy of particle 4 in the center of momentum (mass) frame of 1 and 2 is given by

$$
E_{4 c}=\left(w^{2}-m_{3}^{2} c^{4}+m_{4}^{2} c^{4}\right) /(2 w) \quad
$$

where

$$
w \equiv m_{1} c^{2}+m_{2} c^{2}+q
$$

The rest energies of $1,2,3,4$ are $m_{1} c^{2}, m_{2} c^{2}$, $\mathrm{m}_{3} \mathrm{c}^{2}, \mathrm{~m}_{4} \mathrm{c}^{2} ; \mathrm{q}$ is any additional energy available in the center of momentum (mass) frame of particles 1 and 2 ; and $c$ is the speed of light. The kinetic unergy of 4 is given by

$$
\mathrm{KE}_{4}=\mathrm{E}_{4}-\mathrm{m}_{4} \mathrm{c}^{2} \text {. }
$$

The momentum is given by

$$
\begin{aligned}
P_{4} & =\sqrt{L_{4}^{2}-m_{4}^{2} c^{4}} / c \\
& =\sqrt{k E_{4}\left(2 m_{4} c^{2}+k t_{4}\right)} / c .
\end{aligned}
$$

The velocity of 4 is given by

$$
v_{4}=P_{4} c^{2} / r_{4}
$$

If 1 and 2 have charge numbers $z_{1}$ and $z_{2}$, and if 1 and 2 are in a theimal distribution characterized by a temperature 0 (NicV), $q$ is given by the distribution function which for $0 \ll I$ Me! is approximately $y^{2, \vec{S}}$

$$
S(y) \simeq \operatorname{cxp}\left[-B\left(y-y_{0}\right)^{2}\right\} \quad
$$

where

$$
\begin{aligned}
& \left.4_{0}=(1 / 2)^{2 / 3}: \mathrm{g}^{1 / 3}\right)^{2 / 3}, \\
& \mathrm{~B}=3 /\left(2^{4 / 3} \mathrm{l}_{\mathrm{g}}^{1 / 3} 0^{5 / 3}\right) .
\end{aligned}
$$

$E_{y}$ is the "Gamow energy" which is defined by

$$
I_{g}=2 M\left(\pi z_{1} z_{2} e^{2} / i n\right)^{2}
$$


where $M$ is the reduced mass of 1 and 2 . Evaluat ing this expression,

$$
E_{g}=0.979 \times(\mathrm{MeV}),
$$

where

$$
Y=A Z_{1}^{2} z_{2}^{2}
$$

and

$$
A=A_{1} A_{2} /\left(A_{1}+A_{2}\right)
$$

Here $A_{1}$ and $A_{2}$ are the masses of 1 and 2 in amu.

The expectation value of $q$ is approximately given by

$$
\begin{aligned}
\bar{q} & =q^{0} \\
& =E_{g}^{V / 3} \theta^{2 / 3} / 2^{2 / 3}
\end{aligned}
$$

and the $\Delta q$ about $\bar{q}$ is

$$
\begin{aligned}
\Delta q & =\sqrt{\left\langle q^{2}-\bar{q}^{2}\right\rangle}, \\
& =\sqrt{\frac{1}{2 B}}, \\
& =\frac{1}{\sqrt{3}}\left(2 E_{G}\right)^{1 / 6} 0^{5 / 6}
\end{aligned}
$$

The energy of the center of momentum (mass) frame for 1 and 2 in the laboratory has distribution characterized by the temperature $\theta$. For the decay of this system into particles 5 and 4 where $\mathrm{KE}_{40} \gg \Theta$ and for $\mathrm{KE}_{4} \approx \mathrm{KE}_{40}$, the distribution func$t$ ion is

$$
\begin{aligned}
S\left(K E_{4}\right) & =\exp \left(-\frac{A_{1}+A_{2}}{A_{4}} \frac{K E_{4}+K E_{40}}{\theta}\right) \\
& x \sinh \left(2 \frac{A_{1}+A_{2}}{A_{4}} \frac{\sqrt{K E_{4} K E_{4}}}{\theta}\right)
\end{aligned}
$$

where $\mathrm{KE}_{40}$ is the kinetic energy of particle 4 in the center of momentum (mass) frame.
The expectation value of $\mathrm{KI}_{-}$is givell by

$$
\overline{\mathrm{KE}}=\mathrm{KE} 40+3 / 2 A_{4} /\left(A_{1}+A_{2}\right) ?
$$

and the $\Delta \mathrm{KE}_{4}$ about $\widehat{\mathrm{KE}_{4}}$ is

$$
\Delta K E_{4}=\left[2 \frac{A_{4}}{A_{1}+A_{2}} \theta K E_{40}+3 / 2\left(\frac{A_{4}}{A_{1}+A_{2}}\right)^{2} \theta^{2}\right]^{3 / 2}
$$

or

$$
\Delta K E_{4} \approx \sqrt{\frac{A_{4}}{A_{1}+A_{2}} \odot K E_{40}}
$$

for

$$
k E_{0}>\frac{A_{4}}{A_{1}+A_{2}} \odot
$$

III. NUMERICAL APPLICATIONS TO THE THERHAL UT $\rightarrow$ nW REACTION

The following list gives the atomic masses on a carbon 12 scale. $^{4}$

$\begin{array}{ll}\mathrm{me}_{\mathrm{e}} & 0.000548579 \\ \mathrm{n} & 1.00866522 \\ \mathrm{D} & 2.01410222 \\ \mathrm{~T} & 3.01604972 \\ { }^{4} \mathrm{He} & 4.00260526\end{array}$

The nuclear masses are obtained by correcting for the electron masses and electron binding energics which are $13.595 \mathrm{eV}$ for $\mathrm{H}$ and $54.403 \mathrm{eV}$ for $11 \mathrm{c} .5$

$$
\begin{array}{lllll}
\text { n } & & 1.006 & 665 & 22 \\
0 & 2.015 & 555 & 66 \\
\text { T } & 3.015 & 501 & 16 \\
\alpha & 4.001 & 506 & 16
\end{array}
$$

The conversion from amu to $M c V$ is 1 amu = $931.504 \mathrm{MeV}$. The speed of light used in the calculations is $290.79250 \mathrm{~mm} / \mathrm{ns}$.

Substituting into $\mathrm{lq}$. (15), the expectation value of $q$ is found to be

$$
\bar{j}=0.06470^{2 / 3}(\mathrm{MeV})
$$

where $\odot$ is in MeV. The associated width is fund from Eq. (i8) to be 


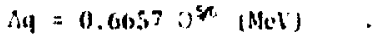

Fropingting if through $1: 4$. (2), the resulting spread in the ceater of momentum frame cnergy is

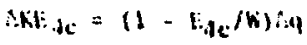

$$
\begin{aligned}
& =.1 / 5.14 \\
& =0.07 \mathrm{MeV} \text { at } 100 \mathrm{keV} \text {. }
\end{aligned}
$$

On the ofher hat. Akt, from kq. (21) is

$$
\begin{aligned}
A K t: & =\sqrt{(3 / 5)(15)} \\
& =0.718 \mathrm{mev} \text { at lou kev. }
\end{aligned}
$$

compiring La. 120) and (28), it is clear that for esaperatures: belon bat ket the effact of the spread of the snorgles calssed by in can bo ignored in commarison to the sperad of encrgies catsed by in , from fist. (21).

The velocity ot the neat roms is desermined by the follawing seluenc. "the $y$ is sallulated froth hat

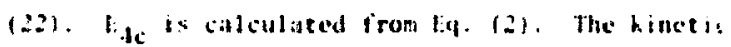

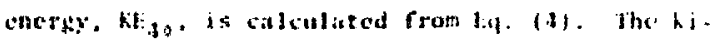
netic cenerg: distrihution in the laboratory, kl g.

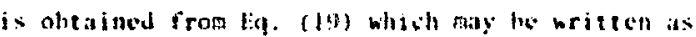

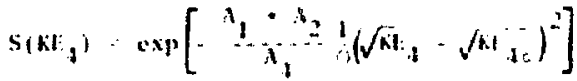

The expestod hinetic enesgy in the lahoratory is given by liq. (20). The neut ron velocity at the $\mathrm{cx}$ pected linetic chersy is ohlathed frotm lips. ist and (6). The belocity distrihutinn maty be oht aned from liq. (29) through the une of ligs. (1), (5), and (6). Near the peak. Jil. (20) may be alproximated by

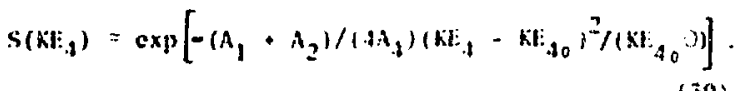

\begin{tabular}{|c|c|c|c|c|}
\hline $\begin{array}{c}D \\
(k \in v)\end{array}$ & $\begin{array}{l}\overline{\mathrm{At}} \\
(\mathrm{NeV}) \\
\end{array}$ & $\begin{array}{l}\text { EXt: } \\
\text { (Mel) }\end{array}$ & $\begin{array}{c}v \\
(1, \mathrm{~m} / \mathrm{ns}) \\
\end{array}$ & $\begin{array}{c}x \\
\text { (mm/ns) }\end{array}$ \\
\hline 0 & 14.0290 & 0.000 & 51.2344 & 0.000 \\
\hline 0.1 & 14.030 & 0.024 & 51.236 & 0.042 \\
\hline 0.2 & 14.031 & $0.03 a$ & 51.238 & 0.060 \\
\hline $0 . \overline{3}$ & 14.0 .31 & 0.043 & 51.239 & 0.075 \\
\hline 0.4 & 14.032 & 0.047 & 51.240 & 0.085 \\
\hline 0.5 & 14.0 .32 & 0.053 & 51.241 & 0.095 \\
\hline 0.6 & 14.05 .5 & 0.058 & 51.24 & 0.10 \\
\hline 0.7 & 14.033 & 0.065 & 51.24 & 0.11 \\
\hline 0.8 & 14.054 & 0.067 & 51.24 & 0.12 \\
\hline 0.9 & 14.0 .34 & 0.071 & $51.2 a$ & 0.1 .5 \\
\hline 1.0 & 1.7 .0 .55 & 0.075 & 51.24 & 0.1 .3 \\
\hline 3.0 & 1.1 .0 .1 & 0.11 & 51.25 & 0.19 \\
\hline 3.0 & 14.04 & 0.15 & 51.26 & 0.25 \\
\hline 1.0 & 14.04 & 0.15 & 51.26 & 0.27 \\
\hline 5.0 & 14.05 & 0.17 & 51.26 & 0.30 \\
\hline 6.0 & 1.2 .015 & 0.18 & 51.27 & 0.5 .5 \\
\hline 90 & 1.05 & 0.20 & 51.27 & 0.35 \\
\hline B. 0 & $1 \div .05$ & 0.21 & 51.28 & 0.58 \\
\hline 9.0 & 1.4 .05 & 0.22 & 51.28 & 0.90 \\
\hline 10.0 & 14.06 & 0.2 .1 & 51.28 & 0.42 \\
\hline$\therefore 0.0$ & 1.07 & 0.34 & 51.51 & 0.60 \\
\hline 50.0 & 12.04 & $0 .+1$ & 51.31 & $0 .-5$ \\
\hline 40.0 & 1.10 & $0 .+8$ & 51.37 & 0.55 \\
\hline 50.0 & 14.12 & 0.53 & 51.39 & 0.45 \\
\hline 60.0 & 1.1 .1 & 0.58 & 51.91 & 1.0 \\
\hline 70.0 & 11.1 .2 & $1) .6 .3$ & 51.1 .5 & 1.1 \\
\hline so). 11 & 14.15 & $0.0^{-}$ & 51.45 & 1.2 \\
\hline M.0 & 11.16 & 11.2 & $\$ 1.37$ & 1.5 \\
\hline 100.0 & 19.17 & 11.5 & 51.49 & 1.5 \\
\hline
\end{tabular}

Table I gives the cxpected neut ron hinstic energy as a function of 0 , the expected $A K l$, the cxpected velocity, ard the $A v$ for the $! \cdot T \cdot$ nu reaction.
TABLI. I

ENERGY AND VILOCITY VS TENPERATUIR:

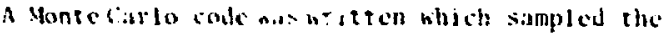
il and $T$ from a Vaxwellain distrihution, craluated the cross sect an to ohtain the reaction prohability and produced the newion isot ropialle in the center of moncheun frame at the 1 and $t$, and transtated the neut ron bach on the lahuratory frams in a relativiseically correct manner. Table /1 compares the saivulated shente carlo results with the numbers from liable 1 .

at I and la kel. thas hinetis cmerpy distrihu-

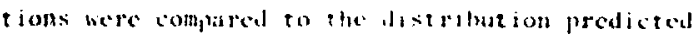

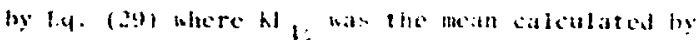


TABLE II

ENERGY AND VELOCITY COMPARED TO THIE RESULTS

OF A MONTE CARLO INTEGRATION

\begin{tabular}{|c|c|c|c|c|c|c|c|c|}
\hline \multirow[b]{2}{*}{$\begin{array}{c}\theta \\
(\mathrm{keV}) \\
\end{array}$} & \multicolumn{2}{|c|}{ Table 1} & \multicolumn{2}{|c|}{ MC Code } & \multicolumn{2}{|c|}{ Table I } & \multicolumn{2}{|c|}{ MC Code } \\
\hline & $\begin{array}{c}\mathrm{KE} \\
(\mathrm{MeV})\end{array}$ & $\begin{array}{c}\triangle K E \\
(\mathrm{MeV})\end{array}$ & $\begin{array}{c}K E \\
(\mathrm{MeV}) \\
\end{array}$ & $\begin{array}{c}\triangle K E \\
(\mathrm{MeV}) \\
\end{array}$ & $\begin{array}{c}y \\
(\mathrm{~mm} / \mathrm{ns}) \\
\end{array}$ & $\begin{array}{c}\Delta v \\
(\mathrm{~mm} / \mathrm{ms}) \\
\end{array}$ & $\begin{array}{c}v \\
(\mathrm{~mm} / \mathrm{ns}) \\
\end{array}$ & $\begin{array}{c}\Delta y \\
(\mathrm{nmm} / \mathrm{ns}) \\
\end{array}$ \\
\hline I & 14.035 & 0.075 & 14.036 & 0.077 & 51.24 & 0.13 & 51.25 & 0.14 \\
\hline 10 & 14.06 & 0.24 & 14.06 & 0.24 & 51.28 & 0.42 & 51.30 & 0.43 \\
\hline 100 & 14.17 & 0.75 & 14.14 & 0.77 & 51.5 & 1.3 & 51.4 & 1.4 \\
\hline
\end{tabular}

the Monte Carlo code. To within the statistics for the calculation, the two distributions agreed.

Table II suggests that the formulae presented here are valid for temperatures in excess of 100 kev.

\section{ACKNOWLEDGMENTS}

The equations have been collected from the work of M. G. Henderson, G. N. Minerbo, D. A. Marshall and P. P. Whalen, with help from the works cited.

\section{REFERENCES}

1. R. Hagedorn, Relativistic Kinematics (w. Benjamin, Inc., New York, 1964), pp 30-32.

2. H. A. Bethe, "Energy Production in Stars," Phys. Today 21, 36 (September 1968).

3. H. A. Fowler, G. R. Culughlan, and B. A. Zimmerman, "Thermonuclear Reaction Rates," Annu. Rev. Astr. Astrophys. 5, 525 (1967).

4. A. W. Wapstra and N. B. Gove, "The 1971 Atomic Mass Evaiuation," Nucl. Data Tables 9, 265 (1971).

5. R. C. Wcast, Handbook of Chemistry and Physics (Chemical Rubber Co., Cleve) and, 1974). 